\title{
Beneficial Effects of Cardiomyopathy-Associated Genetic Variants on Physical Performance: A Hypothesis-Generating Scoping Review
}

\author{
Sjoerd M. Verwijs ${ }^{a} \quad$ Yigal M. Pinto $^{a} \quad$ Diederik W.D. Kuster ${ }^{b}$ \\ Jolanda van der Velden ${ }^{b}$ Jacqueline Limpens ${ }^{c}$ Juliette C. van Hattum ${ }^{a}$ \\ Saskia N. van der Crabben ${ }^{d}$ Ronald H. Lekanne Deprez ${ }^{d}$ Arthur A.M. Wilde ${ }^{a}$ \\ Harald T. Jørstad ${ }^{a}$ \\ aDepartment of Cardiology, Amsterdam UMC, University of Amsterdam, Amsterdam Cardiovascular Sciences, \\ Amsterdam, The Netherlands; ${ }^{b}$ Department of Physiology, Amsterdam UMC, Vrije Universiteit Amsterdam,

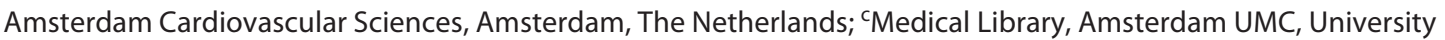

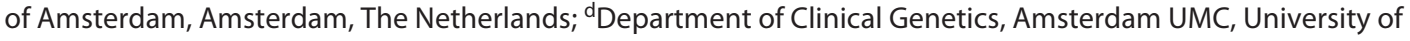 \\ Amsterdam, Amsterdam, The Netherlands
}

\section{Keywords}

Systematic review - Cardiogenetic - Cardiomyopathy .

Physical performance

\begin{abstract}
Background: Genetic variants associated with cardiomyopathies (CMPs) are prevalent in the general population. In young athletes, CMPs account for roughly a quarter of sudden cardiac death, with further unexplained clustering in specific sports. Consequently, most CMPs form a contraindication for competitive sports. We hypothesized that genetic variants might (paradoxically) improve physical performance early in life while impairing cardiac function later in life. Methods: Systematic PubMed search was done to investigate whether genetic variants in genes associated with CMPs could be related to beneficial performance phenotypes. Summary: In a limited number of studies $(n=6), 2,860$ individuals/subjects with genetic variants were able to outperform those without said variants, as measured by running
\end{abstract}

speed ( $38 \mathrm{~m} / \mathrm{min}$ in heterozygous [HET] mice, $n=6$, vs. $\sim 32$ $\mathrm{m} / \mathrm{min}$ in wild type [WT] mice, $n=7, p=0.004$ ) and distance $(966 \pm 169 \mathrm{~km}$ HET mice vs. $561 \pm 144 \mathrm{~km}$ WT mice, $p=0.0035$, $n=10)$, elite athlete status in endurance athletes $(n=1,672$, $\left.p=1.43 \times 10^{-8}\right)$, maximal oxygen uptake in elite athletes (absolute difference not provided, $n=32, p=0.005$ ), maximal oxygen uptake in unrelated individuals ( $n=473, p=0.0025)$, personal records in highly trained marathon runners (2:26:28 \pm 0:06:23 $\min \mathrm{HET}, n=32$, vs. 2:28:53 \pm 0:05:50 min without polymorphism, $n=108, p=0.020$ ), and peripheral muscle force contraction in patients following a cardiac rehabilitation program (absolute values not provided, $n=260$ ). Key Message: Beneficial effects in genetic variants associated with CMPs could hypothetically play a role in the selection of young athletes, consequently explaining the prevalence of such genetic variants in athletes and the general population.
(C) 2021 The Author(s)

Published by S. Karger AG, Basel karger@karger.com www.karger.com/crd

Karger $\stackrel{\text { ' }}{\text { - }}$

BOPEN ACCESS
(C) 2021 The Author(s)

Published by S. Karger AG, Basel

This article is licensed under the Creative Commons Attribution 4.0 International License (CC BY) (http://www.karger.com/Services/ OpenAccessLicense). Usage, derivative works and distribution are permitted provided that proper credit is given to the author and the original publisher.
Correspondence to:

Sjoerd M. Verwijs, s.m.verwijs@amsterdamumc.nl 
Fig. 1. Illustration of study purpose: to investigate whether genetic variants associated with cardiomyopathies relate to any specific beneficial performance phenotypes.

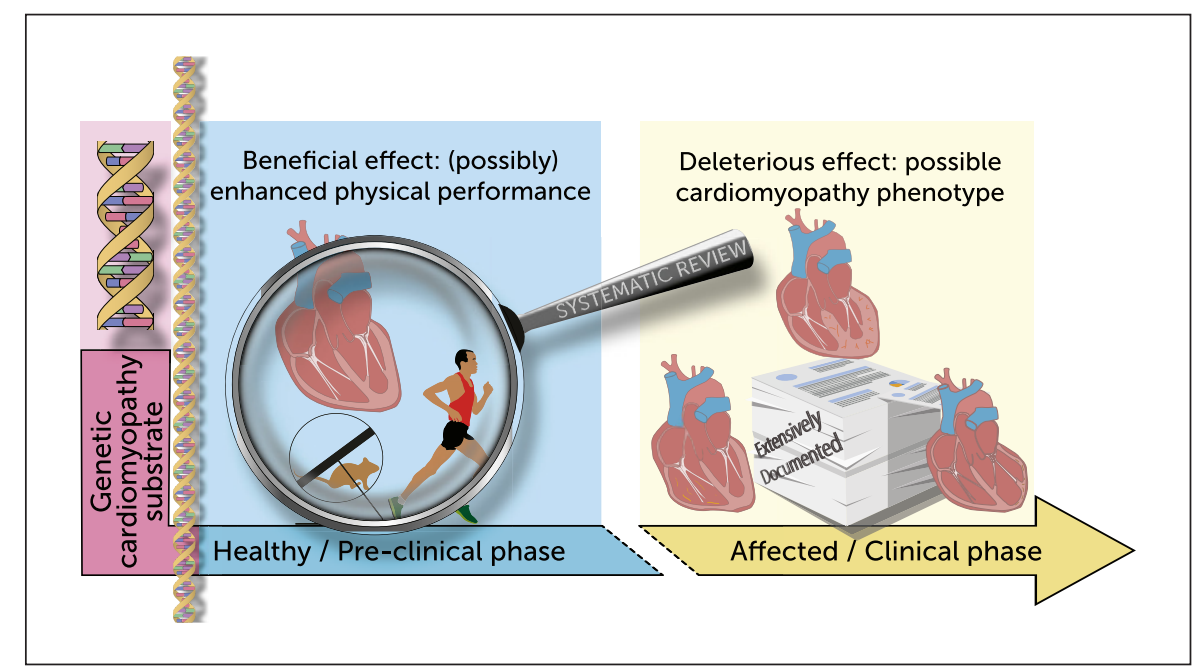

\section{Background}

Genetic cardiomyopathies (CMPs) account for 25\% of sudden cardiac death in young athletes and therefore form a contraindication for numerous competitive sports and intensive exercise [1]. Despite efforts to identify athletes at risk for sudden cardiac death through cardiovascular screening [2], the relatively high frequency of deaths due to CMPs in the athlete population is striking, with further clustering observed in sports such as basketball, soccer, and football [3]. These findings suggest that even after competitive selection and comprehensive screening, athletes with genetic variants that may eventually result in CMPs are still able to perform at elite levels. Furthermore, with prevalence of CMPs and genetic carriers in the general population as high as 1 in 200-500 [4, 5], it might be hypothesized that such variants might be or have been associated with evolutionary benefit, next to the clear negative effects on cardiac health general. To date, there is no adequate explanation for this high prevalence and the seemingly high number of cardiac events in athletes due to CMPs.

Genetic causes that underlie CMPs are continuously being extensively investigated and have been associated with hypertrophic-, dilated-, arrhythmogenic right ventricular-, restrictive-, and noncompaction CMP. Current genetic panels for CMPs investigate about 54 genes [6] and include genes that encode for sarcomere, nuclear membrane, Z-disk, and desmosome.

Both the scientific and sporting communities acknowledge a clear genetic component for (athletic) performance. Maximal oxygen uptake $\left(\mathrm{VO}_{2} \max \right)$ [7], maxi- mal force generation [8], sprint performance [9], and elite endurance performance [10] have all been shown to be (strongly) influenced by genetic traits. However, though a few genes have repeatedly been associated with elite athletic performance [11], genetic screening in athletes remains controversial, as no specific mutations have been reported to strongly predict athletic success [12].

Conversely, in the field of CMPs, negative effects on physical performance and prognosis have been extensively investigated and documented, and genetic testing has become the standard of care for the number of CMPs, with proven diagnostic value $[13,14]$. In general, genetic screening in the absence of comprehensive clinical phenotyping is only advised in specific clinical situations, such as cascade screening [15], and clearly defined research settings.

While the heart of an athlete adapts to training stimuli [16], some hearts may have a predisposition to be better suited for physical exertion. We therefore hypothesized that genetic variants in genes associated with CMPs might (paradoxically) improve physical performance early in life and possibly impair cardiac function only later in life. This could explain why these variants are found relatively frequently in the general population and could, hypothetically, play a role in the selection of high-potential young athletes that train in a highly competitive environment. As the negative effects on physical performance of most CMPs have been extensively documented elsewhere [1], for this scoping review, we aimed to investigate whether genetic variants in CMP genes are associated with any beneficial performance phenotypes (Fig. 1). 
Fig. 2. Search of published research.

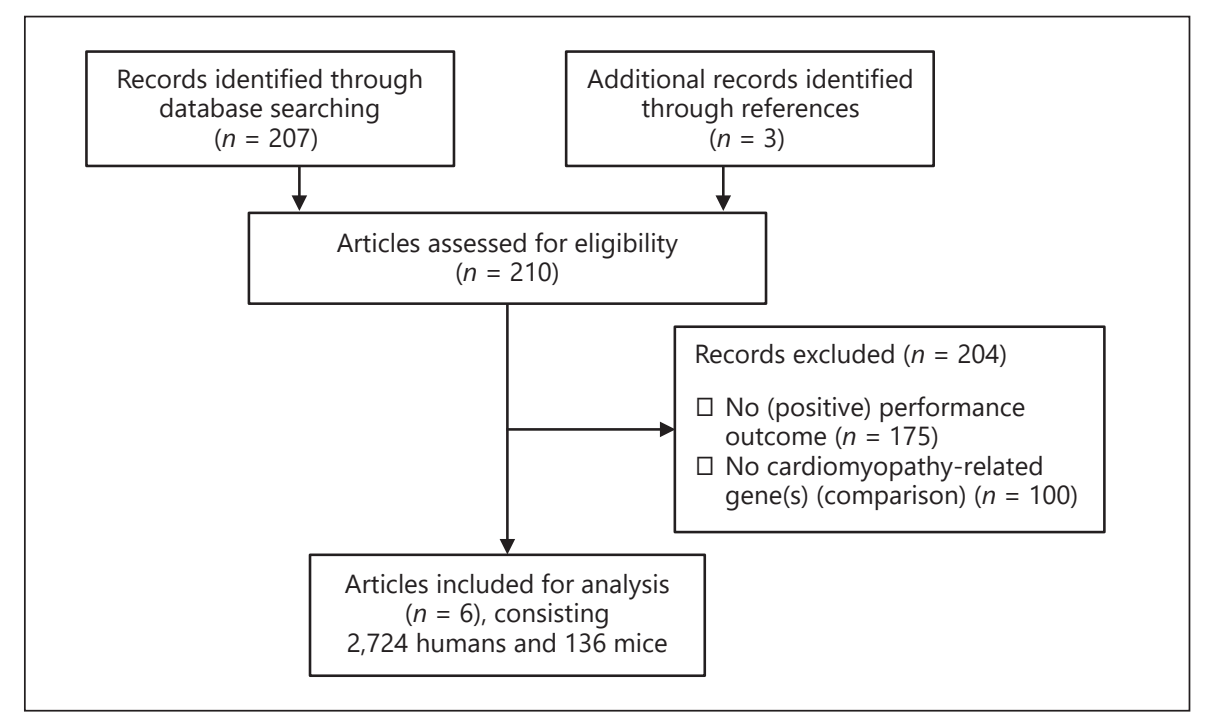

Table 1. Characteristics of included studies [19-24]

\begin{tabular}{|c|c|c|c|c|c|}
\hline First author & Gene (variant) & Included population & Intervention & Measurement & Summary \\
\hline $\begin{array}{l}\text { Methawasin } \\
\text { et al. [19] }\end{array}$ & $\begin{array}{l}\text { RBM20, in-frame } \\
\text { del. exons } 6 \text { and } 7\end{array}$ & $n=13,4$-mo-old mice: $n=6 \mathrm{HET}$ & - & $\begin{array}{l}\text { Maximal treadmill running } \\
\text { speed }\end{array}$ & $\begin{array}{l}\text { Higher maximal running } \\
\text { speed in HET mice }\end{array}$ \\
\hline $\begin{array}{l}\text { Najafi et al. } \\
\text { [20] }\end{array}$ & $\begin{array}{l}\text { MYBPC3, } \\
\text { G>A exon } 6\end{array}$ & $\begin{array}{l}n=40,3 \text {-wk-old mice: } n=5 \text { in } \\
\text { each group: genetic variant, sex, } \\
\text { exercise }\end{array}$ & $\begin{array}{l}\text { 8-week training } \\
\text { program in } \\
\text { exercised group }\end{array}$ & $\begin{array}{l}\text { Treadmill running distance, } \\
\text { cardiomyocyte force } \\
\text { generation }\end{array}$ & $\begin{array}{l}\text { In HET mice: further running } \\
\text { distance + greater } \\
\text { cardiomyocyte force } \\
\text { generation }\end{array}$ \\
\hline $\begin{array}{l}\text { Al-Khelaifi et } \\
\text { al. [21] }\end{array}$ & $\begin{array}{l}\text { MYBPC3, } \\
\text { rs } 1052373\end{array}$ & $\begin{array}{l}n=1,672: n=796 \text { European } \\
\text { international-level athletes, } n= \\
410 \text { elite Russian athletes, } n=60 \\
\text { elite Japanese athletes, } n=406 \\
\text { controls }\end{array}$ & - & $\begin{array}{l}\text { Elite endurance athlete } \\
\text { status, } \mathrm{VO}_{2} \text { max in } \\
\text { subgroup }(n=32)\end{array}$ & $\begin{array}{l}\text { Higher representation of } \\
\text { polymorphism in endurance } \\
\text { athletes }+ \text { higher } \mathrm{VO}_{2} \text { max in } \\
\text { homozygous carriers }\end{array}$ \\
\hline $\begin{array}{l}\text { Stebbings et } \\
\text { al. [22] }\end{array}$ & $\pi N$, rs10497520 & $\begin{array}{l}n=141 \text { male marathon runners: } \\
n=108 \text { without genetic } \\
\text { polymorphism }\end{array}$ & - & $\begin{array}{l}\text { Personal record time for } \\
\text { marathon running }\end{array}$ & $\begin{array}{l}\text { Faster personal best times in } \\
\text { athletes with gene variant }\end{array}$ \\
\hline $\begin{array}{l}\text { Timmons et } \\
\text { al. [23] }\end{array}$ & $\pi N$, rs10497520 & $n=473$ & $\begin{array}{l}\text { 20-week training } \\
\text { program }\end{array}$ & $\Delta \mathrm{VO}_{2} \max$ & $\begin{array}{l}\text { Greater increase in } \mathrm{VO}_{2} \text { max in } \\
\text { polymorphism carriers }\end{array}$ \\
\hline $\begin{array}{l}\text { Thomaes et } \\
\text { al. [24] }\end{array}$ & $\begin{array}{l}\text { TTN, rs10497520 } \\
\text { TPM1, rs707602 }\end{array}$ & $\begin{array}{l}\text { Coronary artery patients: } n=260 \\
\text { at baseline, } n=204 \text { after training }\end{array}$ & $\begin{array}{l}\text { 3-month training } \\
\text { program }\end{array}$ & $\begin{array}{l}\text { Quadriceps force } \\
\text { generation at baseline and } \\
\text { after training }\end{array}$ & $\begin{array}{l}\text { Greater force at baseline in } \\
\text { TTN polymorphism carries }+ \\
\text { greater force increases in } \\
\text { TPM1 polymorphism carriers }\end{array}$ \\
\hline
\end{tabular}

\section{Methods}

We performed a scoping review according to the PRISMA-ScR statement [17]. Our systematic PubMed search through July 2021 consisted of Mesh-terms and text words in the title or abstract (Tiab) for known cardiomyopathy genes and performance outcomes, such as "Physical Endurance," "Muscle Strength," "Athletic Performance," and "Physical Exertion." In addition, we reviewed reference lists for relevant articles. Included genes for hu- man and animal studies were based on typical, current genetic panels for CMPs and included ACTC1, ACTN2, ALPK3, ANKRD1, BAG3, CALR3, CAV3, CDH2, CRYAB, CSRP3, CTNNA3, DES, DSC2, DSG2, DSP, EMD, STA, FHL1, FHL2, FKRP, FLNC, GLA, HCN4, JPH2, JUP, LAMA4, LAMP2, LDB3, LMNA, MIB1, MYBPC3, MYH6, MYH7, MYL2, MYLK3, MYL3, MYOZ2, MYPN, NEXN, PKP2, PLN, PPA2, PRDM16, PRKAG2, RBM20, SCN5A, TAZ, TCAP, TMEM43, TNNC1, TNNI3, TNNI3K, TNNT2, TPM1, TTN, TTR, and VCL (for expansions of gene ab- 


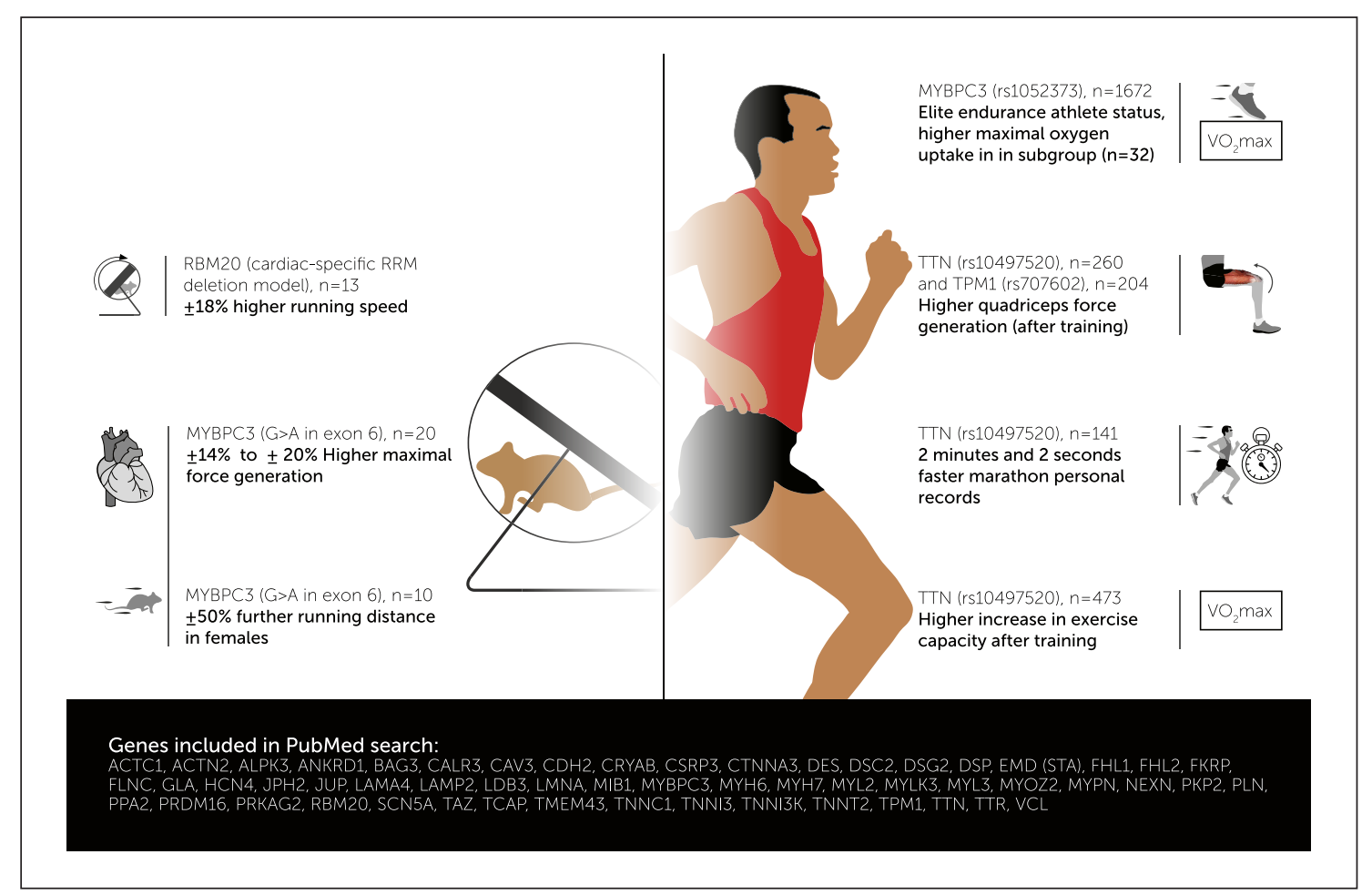

Fig. 3. Overview of beneficial effects of cardiomyopathy-associated genetic variants on physical performance.

breviations, see online suppl. 1; for all online suppl. material, see www.karger.com/doi/10.1159/000520471). Exclusion criteria were (i) no comparison between individuals with and without (a) genetic variant(s) in the above-mentioned gene(s) and (ii) not reporting positive performance outcomes. We did not apply any language restrictions. All publications were independently screened and assessed by authors S.M.V. and H.T.J. Data extraction: for each study, the following data were extracted: first author, the studied gene(s) (variant[s] or polymorphism[s], as appropriate), included population, intervention (if applicable), performed measurements, and summary of positive results.

\section{Statistical Methods}

$p$ values were calculated, if possible, by comparing means, standard deviations, and sample sizes of carriers of genetic variant(s) versus noncarriers, using MedCalc statistical software [18].

\section{Results}

After selection and review, we included 6 articles in the current analysis, comprising 2,724 humans and 136 mice (Fig. 2; Table 1). The included studies reported performance outcomes in 4 genes: RBM20, MYBPC3, TTN, and TPM1 (Fig. 3).

Beneficial Effects of CMP Mutations
Methawasin et al. [19] engineered a mouse model that expresses giant titin proteins, allowing the group to study how titin compliance affects cardiac function in intact cardiomyocytes. In thirteen 4-month-old male mice, maximal treadmill running speed was measured using a rodent treadmill system following a progressively increasing speed protocol. Maximal speed was determined when the mouse left the treadmill and remained on a shock pad. Methawasin et al. [19] found that mice, with a heterozygous (HET) cardiac-specific in-frame deletion in exons 6 and 7 of the Rbm20 gene through homologous recombination, had a $\sim 18 \%$ higher maximum running speed compared with wild type (WT) mice $(\sim 38 \mathrm{~m} / \mathrm{min}$ HET, $n=6$, vs. $\sim 32 \mathrm{~m} / \mathrm{min} \mathrm{WT,} n=7, p=0.004)$.

Najafi et al. [20] reported running distances in a targeted knock-in mouse model, carrying a heterozygous $M y b p c 3$ point mutation ( $\mathrm{G}>\mathrm{A}$ transition on the last nucleotide of exon 6). Five-week-old mice were exposed to an 8-week voluntary wheel-running protocol, and running distances were recorded for each mouse. Voluntary running distances were $~ 50 \%$ longer in HET female mice compared with WT female mice $(966 \pm 169 \mathrm{~km}$ HET vs. $561 \pm 144 \mathrm{~km} \mathrm{WT}, p=0.0035, n=10)$. Both sedentary and exercised female HET mice demonstrated a trend to- 
wards higher maximal cardiomyocyte force generation (sedentary: $20.0 \pm 2.2 \mathrm{kN} / \mathrm{m}^{2}$ HET vs. $17.5 \pm 1.4 \mathrm{kN} / \mathrm{m}^{2}$ $\mathrm{WT}, p=0.0644, n=10$; exercised: $23.1 \pm 1.6 \mathrm{HET}$ vs. 19.2 $\pm 2.3 \mathrm{WT}, p=0.0144, n=10)$ [20].

The group of Al-Khelaifi et al. [21] aimed to investigate the association of multiple single-nucleotide polymorphisms (SNPs) identified using a genome-wide association study in European elite athletes, combined with a replication (of significant SNPs) study in Russian and Japanese elite athletes and Japanese controls $(n=796$, $n=410, n=60$, and $n=406$, respectively). Athletes were classified into different groups of sports following the Mitchell's classification of sports [25]. Meta-analysis of all 4 cohorts confirmed overrepresentation of rs $1052373 \mathrm{GG}$ (MYBPC3) in high endurance $\left(>70 \%\right.$ of $\mathrm{VO}_{2}$ max, according to the Mitchell's classification) elite athletes ( $p=$ $1.43 \times 10^{-8}$, indicating genome-wide association study and Bonferroni levels of significance). Furthermore, homozygous carriers of rs1052373 GG, in Russian elite athletes with available $\mathrm{VO}_{2}$ max data $(n=32 ; 17$ females), had a significantly greater $\mathrm{VO}_{2}$ max than carriers of AG or AA ( $p=0.005$, adjusted for sex). The (difference in) $\mathrm{VO}_{2}$ max values were not reported [21].

In 141 unrelated, Caucasian, highly trained (Olympic-, international-, and national-level) male marathon runners, personal record marathon times were recorded. Each participant was genotyped for the TTN rs 10497520 C $>$ T polymorphism, using real-time polymerase chain reaction. Independent samples $t$ tests were conducted to identify any genotype differences in personal best times and demonstrated that marathon runners with the polymorphism were 2:02 min faster compared to individuals without the polymorphism (2:26:28 \pm 0:06:23 min HET polymorphism, $n=32$, vs. 2:28:53 $\pm 0: 05: 50 \mathrm{~min}$ without polymorphism, $n=108, p=0.020$ ) [22].

Timmons et al. [23] aimed to investigate SNPs that could explain the heterogeneity in $\mathrm{VO}_{2}$ max response in 473 apparently healthy Caucasian participants ( $243 \mathrm{fe}-$ male and 230 male) who completed a 20 -week customized training program. Following 2 sequential, independent pilot studies (the second to validate the first) in 41 subjects that underwent a supervised customized endurance training program, a panel of 29 genes was tested. After adjusting the increase in $\mathrm{VO}_{2}$ max for sex, age, baseline body weight, and baseline maximal oxygen consumption, a greater increase of $\mathrm{VO}_{2}$ max after training was shown in carriers of the TTN rs $10497520 \mathrm{C}>\mathrm{T}$ polymorphism (partial correlation coefficient 0.0204; stepwise regression model correlation coefficient $0.1146, p=$ $0.0025)$ [23].
Thomaes et al. [24] investigated a "genetic predisposition score," based on earlier identified polymorphisms for different muscular phenotypes that could explain individual differences in muscular fitness and the response to training in patients with coronary artery disease. $\mathrm{Pa}$ tients were genotyped for the panel of earlier identified polymorphisms and followed a standard ambulatory supervised cardiac rehabilitation program for 3 months. TTN rs10497520 ( $n=260$ at baseline, 37 female and 223 male) and TPM1 rs707602 ( $n=204$ after training) were found to significantly contribute to genetic predisposition scores and were associated with greater quadriceps force generation at baseline and after 3 months of training, respectively (absolute values for isolated polymorphisms not reported) [24].

\section{Discussion}

With this first review on beneficial effects on physical performance of genetic variants found in genes involved in CMPs, we identified possible positive effects on different aspects related to performance. In mice models, our study identified associations between $R b m 20$ with increased running speed, and between $M y b p c 3$ targeted knock-in with increased voluntary running distance and increased maximal cardiomyocyte force generation. In humans, we found MYBPC3 to be associated with an increased $\mathrm{VO}_{2}$ max in elite-level endurance athletes and high endurance elite athlete status; TTN with faster marathon personal best times in highly trained marathon runners; TTN with a greater increase of $\mathrm{VO}_{2}$ max after a training program in healthy participants; TTN in coronary artery patients with a greater quadriceps force generation at baseline; and TPM1 with a greater quadriceps force generation after 3 months of training.

Our findings of improvements in physical performance in individuals with genetic variants in CMP-associated genes constitute a different angle of investigations into the complex interplay between physical exercise and sports and genetic substrates. Hypothetically, an evolutionary benefit in the healthy/preclinical phase and only later deleterious effects on physical performance might be one of the explanations for the relatively high prevalence of CMPs in the general population. Similar to the protective effect of minor phenotypes of sickle cell and thalassemia anemia against malaria, such a beneficial effect might come at a price [26]. Subtle positive effects on physical performance could at first provide young athletes, who train in a highly competitive environment, with a 
slight advantage when competing against athletes without these genetic variant(s), but might later lead to a higher prevalence of CMPs and sudden cardiac death. Similarly, one could hypothesize on comparable effects in different ethnic groups. Athletes from African or Afro-Caribbean regions have a different cardiac physiology and pathophysiology compared with athletes from Asian and European regions. Currently, all but one of the men's world records running (100-m sprint up until the full marathon) are held by athletes representing African or Afro-Caribbean countries, whereas the majority of competitive athletes who die from hypertrophic CMPs are found to be from identical regions [27, 28]. Additionally, in a retrospective study (1999-2014) of 508,108 athletes, Ethiopian and Kenyan athletes (both male and female) achieved the fastest half- and full-marathon times, despite accounting for $<0.1 \%$ of participants [29]. Theoretically, a RBM20 haploinsufficiency could predispose an athlete to a cardiac phenotype with an increased TTN compliance and be able to run faster (beneficial effect) [19], while making some athletes susceptible to developing (arrhythmogenic) dilated cardiomyopathy later in life (deleterious effect) [30, 31]. However, the extent and the juncture in life of the beneficial effect, as well as the risk of developing pathology, remains highly unclear.

There is currently no unequivocal causal relationship between the identified genetic variants in our study and the clinical expression of CMPs. However, several mechanisms of pathogenic variants in genes associated with CMPs have been documented or suggested, including the genes described in this document: RMB20 (RNA Binding Motif protein 20), MYBPC3 (the gene encoding cardiac myosin-binding protein C), TTN (titin), and TPM1 (tropomyosin 1).

First, variants in RBM20, a heart- and skeletal muscleenriched splicing factor controlling tissue-specific isoform expression, have been shown to result in an arrhythmogenic dilated CMP $[32,33]$. Similar to the mouse model as investigated by Methawasin et al. [19], a genetic variant resulting in haploinsufficiency (i.e., partial inactivation) in RBM20 could present itself as a likely mechanism for dilated CMP in humans [30, 31]. Second, approximately $40 \%$ of identified hypertrophic CMP variants are found in the MYBPC3 gene, which encodes a thick filament-associated protein. The Mybpc3 mouse model as investigated by Najafi et al. [20] is highly similar to the proven pathogenic human genetic variant associated with a severe hypertrophic CMP phenotype with poor prognosis $[34,35]$. Third, truncating variants in titin (TTN), the largest protein described to date and the "elas- tic" filament of the sarcomere, play important roles in the pathogenesis of CMPs and heart failure [36-38]. In humans, a TTN missense variant, as investigated by Stebbings et al. [22], Timmons et al. [23], and Thomaes et al. [24], has been identified. Finally, TPM1 is a protein involved in calcium-activated muscle contraction. When calcium is absent, tropomyosin blocks the binding site on actin for myosin [39]. Pathogenic variants in TPM1 have been associated with hypertrophic and dilated CMP [40].

According to the Genome Aggregation Database, the SNPs rs10497520 (TTN), rs1052373 (MYBPC3), and rs707602 (TMP1) are currently considered benign variants. However, the relevance of polymorphisms/frequently found genetic variants - such as the discussed rs10497520 missense mutation - in developing CMPs is still unclear, and although there is not enough data to conclude on a possible role of this variant in absence of a pathogenic effect, firm conclusions about a possible positive effect cannot be drawn either.

\section{Strengths and Limitations}

There are several strengths to our study. First, our review highlights a period in the athlete's life radically different compared with more conventional studies, which are focused on the negative effects of genetic variants (Fig. 1). Second, we used a systematic and broad approach following the PRISMA-ScR statement to identify relevant articles. No filters were applied to increase the chances of finding articles of relevance. Third, the included studies provided detailed information on the investigated genetic variants, allowing for detailed replication in future research. Finally, our analysis included a large number of included individuals, both animals and humans.

A number of aspects of our review warrant consideration. First, the beneficial effects identified in our study were found in a limited number of studies of which most were not specifically designed to investigate positive (athletic) performance outcomes in individuals/subjects with CMP-related genetic variants, with the exemption of the studies of Al-Khelaifi et al. [21] and Stebbings et al. [22]. The limited number of found studies prevents drawing firm conclusions regarding possible beneficial effects of genetic variants in genes associated with CMPs. More importantly, this may be indicative of citation bias or selective reporting, as conventionally, positive performance outcomes in the preclinical phase of genetic CMPs are seldom to never rigorously investigated. In line with our study question, the search strategy and inclusion criteria were broad and exclusion criteria specific (excluding studies with negative outcome measures), in order to op- 
timize identification of all possible studies reporting beneficial effects of cardiomyopathy-associated genetic variants and polymorphisms on physical performance. With this strategy, we aimed to investigate whether there is any evidence (at all) to support our hypothesis. Consequently, our study was limited to only positive effects (Fig. 1).

Second, the effects of exercise on developing pathology in individuals or subjects with cardiomyopathy-associated genetic variants (that display a beneficial effect on physical performance) are unclear. One could hypothesize that exercise is eventually harmful, which might explain the limited number of studies we identified. In line with this, physical exercise has been shown to contribute to the development of arrhythmogenic CMP phenotypes in individuals with variants in PKP2 or DSG2 [13, 41]. However, for subclinical or preclinical hypertrophic or dilated CMPs, such negative associations remain highly contested, and the current ESC guidelines recommend continued participation in exercise and sports in most main groups of preclinical CMPs [1]. Within our analysis, most (5 out of 6 ) reports were not designed to test such hypotheses. The studies of AlKhelaifi et al. [21], Thomaes et al. [24], Timmons et al. [23], and Stebbings et al. [22] did not include the onset of any symptoms (including death). The mice of Najafi et al. [20] were euthanized, and Methawasin et al. [19] reported normal life spans in their mice. Therefore, based on the findings in these individuals/subjects, we cannot deduce the effects of exercise on the development of pathological phenotypes.

Third, the greater maximum cardiomyocyte force generation in mice found by Najafi et al. [20] was not found in male mice, suggesting a sexual dimorphic effect. The beneficial or negative effects may present themselves differently in female or male individuals/subjects. Unfortunately, most of the currently included small number of studies do not provide results with stratification based on sex and therefore do not allow for further analyses on sex differences in physical performance in the presence of $\mathrm{CMP}$-associated genetic variant(s).

Finally, and possibly most importantly, the identified studies were highly heterogeneous. Two studies were performed in mice, while 4 studies were performed in heterogeneous groups of humans. The association of RBM20 and TPM1 with positive performance outcomes was also described in separate articles. Additionally, varying outcome measures were used, and the outcome measure that was used in multiple articles $\left(\mathrm{VO}_{2} \max \right)$ was measured using different protocols. Finally, no association was replicated in a second study, limiting generalizability.

\section{Conclusion}

Genetic variants in RBM20, MYBPC3, TTN, and TPM1 are possibly associated with beneficial effects on physical performance, as shown in a limited number of heterogeneous studies. These findings should be interpreted with caution and warrant further investigation to elucidate the complex interplay between performance and (preclinical) CMPs. Future (basic) prospective research projects focused on pleiotropic effects of CMP-related polymorphisms, such as possible beneficial effects prior to pathogenic and negative effects, are necessary to further substantiate our hypothesis.

\section{Conflict of Interest Statement} clare.

All authors report that they have no conflicts of interest to de-

\section{Funding Sources}

Harald Jørstad has received funding from the Amsterdam Movement Sciences (P1A210AMC2018) and the National Olympic Committee and National Sports Federation.

\section{Author Contributions}

Sjoerd M. Verwijs is the main author. Yigal M. Pinto contributed to conception and design. Diederik W.D. Kuster contributed to acquisition and interpretation. Jolanda van der Velden contributed to acquisition and interpretation. Jacqueline Limpens contributed to design. Juliette C. van Hattum contributed to design and interpretation. Saskia N. van der Crabben contributed to acquisition and interpretation. Ronald H. Lekanne Deprez contributed to acquisition and interpretation. Arthur A.M. Wilde contributed to conception and design. Harald T. Jørstad contributed to conception, design, acquisition, and interpretation.

References

Cardiology 2022;147:90-97 DOI: $10.1159 / 000520471$
1 Pelliccia A, Sharma S, Gati S, Bäck M, Börjesson M, Caselli S, et al.; ESC Scientific Document Group. 2020 ESC guidelines on sports cardiology and exercise in patients with cardiovascular disease. Eur Heart J. 2021;42(1): 17-96.

2 Toresdahl BG, Asif IM, Rodeo SA, Ling DI, Chang CJ. Cardiovascular screening of olympic athletes reported by chief medical officers of the Rio 2016 olympic games. Br J Sports Med. 2018;52(17):1097.

3 Wasfy MM, Hutter AM, Weiner RB. Sudden cardiac death in athletes. Methodist Debakey Cardiovasc J. 2016;12(2):76-80.
Verwijs et al. 
4 McKenna WJ, Maron BJ, Thiene G. Classification, epidemiology, and global burden of cardiomyopathies. Circ Res. 2017;121(7): 722-30.

5 Semsarian C, Ingles J, Maron MS, Maron BJ. New perspectives on the prevalence of hypertrophic cardiomyopathy. J Am Coll Cardiol. 2015;65(12):1249-54.

6 van Lint FHM, Mook ORF, Alders M, Bikker H, Dit Deprez RHL, Christiaans I. Large nextgeneration sequencing gene panels in genetic heart disease: yield of pathogenic variants and variants of unknown significance. Neth Heart J. 2019;27(6):304-9.

7 Bouchard C, Sarzynski MA, Rice TK, Kraus WE, Church TS, Sung YJ, et al. Genomic predictors of the maximal $\mathrm{O}_{2}$ uptake response to standardized exercise training programs. J Appl Physiol. 2011;110(5):1160-70.

8 Zarbska A, Sawczyn S, Kaczmarczyk M, Ficek K, Maciejewska-Karowska A, Sawczuk M, et al. Association of rs699 (M235T) polymorphism in the AGT gene with power but not endurance athlete status. J Strength Cond Res. 2013;27(10):2898-903.

9 Yang N, MacArthur DG, Gulbin JP, Hahn AG, Beggs AH, Easteal S, et al. ACTN3 genotype is associated with human elite athletic performance. Am J Hum Genet. 2003;73(3): $627-31$.

10 Ahmetov I, Kulemin N, Popov D, Naumov V, Akimov E, Bravy Y, et al. Genome-wide association study identifies three novel genetic markers associated with elite endurance performance. Biol Sport. 2015;32(1):3-9.

11 Malsagova KA, Butkova TV, Kopylov AT, Izotov AA, Rudnev VR, Klyuchnikov MS, et al. Molecular portrait of an athlete. Diagnostics. 2021;11(6):1095.

12 Guth LM, Roth SM. Genetic influence on athletic performance. Curr Opin Pediatr. 2013; 25(6):653-8.

13 Costa S, Gasperetti A, Medeiros-Domingo A, Akdis D, Brunckhorst C, Saguner AM, et al. Familial arrhythmogenic cardiomyopathy: clinical determinants of phenotype discordance and the impact of endurance sports. J Clin Med. 2020;9(11):3781.

14 Tintelenvan JP, Entius MM, Bhuiyan ZA, Jongbloed R, Wiesfeld ACP, Wilde AAM, et al. Plakophilin-2 mutations are the major determinant of familial arrhythmogenic right ventricular dysplasia/cardiomyopathy. Circulation. 2006;113(13):1650-8.

15 Gray B, Semsarian C. Utility of genetic testing in athletes. Clin Cardiol. 2020;43(8):915-20.

16 Gerche AL, Heidbuchel H. Can intensive exercise harm the heart? Circulation. 2014; 130(12):992-1002.

17 Tricco AC, Lillie E, Zarin W, O'Brien KK, Colquhoun $\mathrm{H}$, Levac D, et al. PRISMA extension for scoping reviews (PRISMA-ScR): checklist and explanation. Ann Intern Med. 2018;169(7):467-73.
18 MedCalc Software Ltd. Comparison of means calculator [Internet]. 2021 [cited $2020 \mathrm{Dec}$ 31]. Available from: https://www.medcalc. org/calc/comparison_of_means.php.

19 Methawasin M, Hutchinson KR, Lee EJ, Smith JE, Saripalli C, Hidalgo CG, et al. Experimentally increasing titin compliance in a novel mouse model attenuates the frank-starling mechanism but has a beneficial effect on diastole. Circulation. 2014;129(19):1924-36.

20 Najafi A, Schlossarek S, van Deel ED, van den Heuvelvan den N, Güçlü A, Goebel M, et al. Sexual dimorphic response to exercise in hypertrophic cardiomyopathy-associated MYBPC3-targeted knock-in mice. Pflugers Arch. 2015;467(6): 1303-17.

21 Al-Khelaifi F, Yousri NA, Diboun I, Semenova EA, Kostryukova ES, Kulemin NA, et al. Genome-wide association study reveals a novel association between MYBPC3 gene polymorphism, endurance athlete status, aerobic capacity and steroid metabolism. Front Genet. 2020;11:595.

22 Stebbings GK, Williams AG, Herbert AJ, Lockey SJ, Heffernan SM, Erskine RM, et al. TTN genotype is associated with fascicle length and marathon running performance. Scand J Med Sci Sports. 2018;28(2):400-6.

23 Timmons JA, Knudsen S, Rankinen T, Koch LG, Sarzynski M, Jensen T, et al. Using molecular classification to predict gains in maximal aerobic capacity following endurance exercise training in humans. J Appl Physiol. 2010;108(6):1487-96.

24 Thomaes T, Thomis M, Onkelinx S, Goetschalckx K, Fagard R, Lambrechts D, et al. Genetic predisposition scores associate with muscular strength, size, and trainability. Med Sci Sports Exerc. 2013;45(8):1451-9.

25 Mitchell JH, Haskell W, Snell P, Van Camp SP. Task force 8: classification of sports. J Am Coll Cardiol. 2005;45(8):1364-7.

26 Kariuki SN, Williams TN. Human genetics and malaria resistance. Hum Genet. 2020; 139(6-7):801-11.

27 World Athletics. World records - men outdoor [Internet]. $2021 \mathrm{Jul}$ [cited $2021 \mathrm{Jul}$ 12]. Available from: https://www.worldathletics. org/records/by-category/world-records.

28 Maron BJ, Carney KP, Lever HM, Lewis JF, Barac I, Casey SA, et al. Relationship of race to sudden cardiac death in competitive athletes with hypertrophic cardiomyopathy. J Am Coll Cardiol. 2003;41(6):974-80.

29 Knechtle B, Nikolaidis PT, Onywera VO, Zingg MA, Rosemann T, Rüst CA. Male and female Ethiopian and Kenyan runners are the fastest and the youngest in both half and full marathon. Springerplus. 2016;5(1):223.
30 Guo W, Schafer S, Greaser ML, Radke MH, Liss M, Govindarajan T, et al. RBM20, a gene for hereditary cardiomyopathy, regulates titin splicing. Nat Med. 2012;18(5):766-73.

31 Beqqali A, Bollen IA, Rasmussen TB, van den Hoogenhof MM, van Deutekom HW, Schafer $\mathrm{S}$, et al. A mutation in the glutamate-rich region of RNA-binding motif protein 20 causes dilated cardiomyopathy through missplicing of titin and impaired Frank-Starling mechanism. Cardiovasc Res. 2016;112(1):452-63.

32 van den Hoogenhof MMG, Beqqali A, Amin AS, van der Made I, Aufiero S, Khan MAF, et al. RBM20 mutations induce an arrhythmogenic dilated cardiomyopathy related to disturbed calcium handling. Circulation. 2018; 138(13):1330-42.

33 Hershberger RE, Hedges DJ, Morales A. Dilated cardiomyopathy: the complexity of a diverse genetic architecture. Nat Rev Cardiol. 2013;10(9):531-47.

34 Richard P, Charron P, Carrier L, Ledeuil C, Cheav T, Pichereau C, et al. Hypertrophic cardiomyopathy: distribution of disease genes, spectrum of mutations, and implications for a molecular diagnosis strategy. Circulation. 2003;107(17):2227-32.

35 Andersen PS, Havndrup O, Bundgaard $\mathrm{H}$, Larsen LA, Vuust J, Pedersen AK, et al. Genetic and phenotypic characterization of mutations in myosin-binding protein C (MYBPC3) in 81 families with familial hypertrophic cardiomyopathy: total or partial haploinsufficiency. Eur J Hum Genet. 2004;12(8):673-7.

36 Vikhlyantsev IM, Podlubnaya ZA. New titin (connectin) isoforms and their functional role in striated muscles of mammals: facts and suppositions. Biochemistry. 2013;77(13): 1515-35.

37 Roberts AM, Ware JS, Herman DS, Schafer S, Baksi J, Bick AG, et al. Integrated allelic, transcriptional, and phenomic dissection of the cardiac effects of titin truncations in health and disease. Sci Transl Med. 2015;7(270): 270ra6.

38 Schafer S, de Marvao A, Adami E, Fiedler LR, $\mathrm{Ng} \mathrm{B}$, Khin E, et al. Titin-truncating variants affect heart function in disease cohorts and the general population. Nat Genet. 2016; 49(1):46-53.

39 Baynes J, Dominiczak MH. Medical biochemistry. 2009.

40 Tardiff JC, Robbins J, Seidman C, Watkins H. Thin filament mutations: developing an integrative approach to a complex disorder. Circ Res. 2011;108(6):765-82.

41 Cruz FM, Sanz-Rosa D, Roche-Molina M, García-Prieto J, García-Ruiz JM, Pizarro G, et al. Exercise triggers ARVC phenotype in mice expressing a disease-causing mutated version of human plakophilin-2. J Am Coll Cardiol. 2015;65(14):1438-50. 